\title{
Erratum to: The prospects of fare-free public transport: evidence from Tallinn
}

\author{
Oded Cats $^{1,2} \cdot$ Yusak O. Susilo $^{2} \cdot$ Triin Reimal $^{3}$
}

\section{Erratum to: Transportation DOI 10.1007/s11116-016-9695-5}

Unfortunately several errors appeared in Table 2 in the original publication of this article. The corrected Table 2 is given in this erratum.

The online version of the original article can be found under doi:10.1007/s11116-016-9695-5.

\author{
Oded Cats \\ o.cats@tudelft.nl \\ Yusak O. Susilo \\ yusak.susilo@abe.kth.se \\ Triin Reimal \\ triin.reimal@ramboll.se
}

1 Department of Transport and Planning, Delft University of Technology, P.O. Box 5048, 2600 GA Delft, The Netherlands

2 Department of Transport Science, KTH Royal Institute of Technology, Teknikringen 10, 11428 Stockholm, Sweden

3 Ramböll AB, Krukmakargatan 21, 10462 Stockholm, Sweden 
Table 2 Modal split by user group

\begin{tabular}{|c|c|c|c|c|c|c|c|c|c|c|c|}
\hline & \multicolumn{5}{|c|}{ Fall 2012} & \multicolumn{5}{|c|}{ Fall 2013} & \multirow{2}{*}{$\begin{array}{l}\text { Increase in PT } \\
\text { share }(\%)\end{array}$} \\
\hline & PT & Car & Walk & Bike & Oth. & PT & Car & Walk & Bike & Oth. & \\
\hline Total & 55 & 32 & 12 & 1 & 1 & 63 & 29 & 7 & 1 & 1 & 14 \\
\hline \multicolumn{12}{|l|}{ Gender $(\%)$} \\
\hline Men & 43 & 44 & 11 & 1 & 1 & 49 & 41 & 7 & 1 & 1 & 14 \\
\hline Women & 64 & 22 & 13 & 1 & 1 & 71 & 20 & 8 & 0 & 1 & 11 \\
\hline \multicolumn{12}{|l|}{ Age group (\%) } \\
\hline 15-19 years old & 66 & 9 & 23 & 0 & 1 & 80 & 7 & 13 & 0 & 0 & 21 \\
\hline 20-29 years old & 58 & 32 & 9 & 1 & 0 & 62 & 26 & 9 & 2 & 1 & 7 \\
\hline 30-39 years old & 42 & 49 & 8 & 0 & 0 & 44 & 48 & 7 & 1 & 0 & 5 \\
\hline $40-49$ years old & 43 & 41 & 15 & 1 & 0 & 50 & 39 & 10 & 0 & 1 & 16 \\
\hline 50-59 years old & 54 & 36 & 8 & 0 & 1 & 59 & 33 & 6 & 1 & 0 & 9 \\
\hline 60-74 years old & 64 & 22 & 13 & 1 & 1 & 76 & 18 & 5 & 0 & 0 & 19 \\
\hline 75 years old or older & 71 & 7 & 19 & 1 & 2 & 82 & 10 & 6 & 0 & 3 & 15 \\
\hline \multicolumn{12}{|l|}{ Net monthly income (\%) } \\
\hline Up to $300 €$ & 65 & 12 & 21 & 0 & 2 & 82 & 12 & 5 & 0 & 0 & 26 \\
\hline $301-400 €$ & 63 & 25 & 11 & 1 & 1 & 72 & 20 & 6 & 0 & 1 & 14 \\
\hline $401-650 €$ & 59 & 34 & 8 & 0 & 0 & 58 & 31 & 8 & 2 & 1 & -2 \\
\hline $651-1000 €$ & 39 & 52 & 7 & 1 & 1 & 42 & 50 & 6 & 1 & 2 & 8 \\
\hline $1000 €+$ & 39 & 59 & 2 & 0 & 0 & 31 & 50 & 18 & 0 & 2 & -21 \\
\hline No answer & 49 & 36 & 13 & 1 & 1 & 59 & 31 & 9 & 0 & 0 & 20 \\
\hline \multicolumn{12}{|l|}{ Primary occupation } \\
\hline Working & 48 & 43 & 8 & 1 & 0 & 54 & 38 & 7 & 1 & 1 & 13 \\
\hline Pensioner & 69 & 12 & 16 & 1 & 2 & 81 & 11 & 6 & 0 & 2 & 17 \\
\hline Home/parental leave & 39 & 39 & 22 & 0 & 0 & 47 & 34 & 19 & 0 & 0 & 21 \\
\hline Student & 73 & 9 & 18 & 0 & 1 & 76 & 11 & 13 & 0 & 0 & 4 \\
\hline Unemployed & 53 & 24 & 20 & 2 & 2 & 70 & 15 & 9 & 3 & 3 & 32 \\
\hline \multicolumn{12}{|c|}{ Car available per household (\%) } \\
\hline None & 79 & 1 & 17 & 1 & 1 & 88 & 1 & 8 & 1 & 1 & 11 \\
\hline 1 car & 43 & 47 & 8 & 0 & 1 & 43 & 50 & 7 & 0 & 0 & 0 \\
\hline 2 or more cars & 22 & 71 & 6 & 0 & 0 & 24 & 69 & 5 & 1 & 1 & 9 \\
\hline \multicolumn{12}{|l|}{ Registered residency } \\
\hline Tallinn & 55 & 32 & 12 & 1 & 1 & 64 & 28 & 7 & 1 & 1 & 16 \\
\hline Elsewhere & 52 & 36 & 11 & 0 & 1 & 34 & 50 & 15 & 0 & 1 & -35 \\
\hline
\end{tabular}

